\title{
Identifying Risk for Attrition during Treatment for Depression
}

\author{
Diane Warden $^{\mathrm{a}}$ Madhukar H. Trivedi $^{\mathrm{a}}$ Stephen R. Wisniewski ${ }^{\mathrm{c}}$ Ira M. Lesser ${ }^{\mathrm{d}}$ \\ Jeff Mitchelle G.K. Balasubramani ${ }^{c}$ Maurizio Fava ${ }^{f}$ Kathy Shores-Wilson ${ }^{a}$ \\ Diane Stegman $^{\mathrm{a}}$ A. John Rush ${ }^{\mathrm{a}, \mathrm{b}, \mathrm{g}}$
}

\begin{abstract}
Departments of a Psychiatry and ${ }^{b}$ Clinical Sciences, University of Texas Southwestern Medical Center at Dallas, Dallas, Tex., 'Epidemiology Data Center, Graduate School of Public Health, University of Pittsburgh, Pittsburgh, Pa., ${ }^{\mathrm{d} D e p a r t m e n t}$ of Psychiatry and Los Angeles Biomedical Research Institute at Harbor-UCLA Medical Center, Torrance, Calif., e Laureate Psychiatric Clinic and Hospital, Tulsa, Okla., and ${ }^{\mathrm{f} C l i n i c a l ~ P s y c h o p h a r m a c o l o g y ~ U n i t, ~}$ Massachusetts General Hospital, Boston, Mass., USA; ${ }^{9}$ Duke-National University of Singapore, Singapore
\end{abstract}

\section{Key Words}

Attrition $\cdot$ Adherence $\cdot$ Depression $\cdot$ Antidepressant $\cdot$ Attitudes

\begin{abstract}
Background: Understanding patients' ambivalence about treatment persistence may be useful in tailoring retention interventions for individual patients with major depressive disorder. Methods: Participants $(n=265)$ with major depressive disorder were enrolled into an 8-week trial with a selective serotonin reuptake inhibitor. At baseline and week 2 , the participants were asked about their intent to return for the next visit, complete the study and continue in the study should they experience side effects or no improvement. Dropouts were defined as participants who discontinued attending clinic visits before completing the trial. Results: Participants who at baseline reported an uncertain/negative intent to continue if they experienced side effects or no improvement dropped out at a significantly higher rate by weeks 6 and 8 . Uncertain/negative intent at week 2 predicted attrition at all following visits. Dropouts without side effects were more likely to have reported an uncertain/negative intent to attend at both baseline and week 2, while dropouts who experienced side effects were more likely to
\end{abstract}

have reported an uncertain/negative intent to attend only at baseline. Positive intent to continue was associated with greater symptom improvement in both dropouts and completers despite the possibility of lack of efficacy. Conclusions: Participants' pretreatment concerns about continuing antidepressant treatment in the presence of side effects signals challenges to the completion of a full 8-week acute phase treatment, even if the participant does not develop side effects. Individualized review of concerns and tailoring appropriate interventions may be necessary to reduce attrition.

Copyright $\odot 2009$ S. Karger AG, Basel

\section{Introduction}

Attrition, or leaving treatment prematurely, is a substantial problem in the treatment of major depressive disorder (MDD) [1]. The attrition rates in the first 12 weeks of treatment can be as high as $65 \%$ in naturalistic settings [2-4] and $36 \%$ in clinical trials [5], and as many as $15 \%$ of the patients never begin a prescribed antidepressant [6]. These high attrition rates are disturbing given that patients who leave treatment are less likely to reach remission [7-9], have poorer functioning [10] and are more

\section{KARGER}

두 2009 S. Karger AG, Basel

Fax +41613061234

E-Mail karger@karger.ch

www.karger.com
Accessible online at: www.karger.com/pps
Diane Warden, PhD, MBA

Department of Psychiatry, University of Texas Southwestern Medical Center at Dallas 5323 Harry Hines Blvd., Dallas, TX 75390-9119 (USA)

Tel. +1 214648 4614, Fax +1 2146480168

E-Mail Diane.Warden@UTSouthwestern.edu 
likely to relapse [11]. Clearly, it would be beneficial to develop interventions to reduce attrition. The recent focus on personalized medicine [12] highlights the importance of asking not what is best for the hypothetical typical patient, but rather what is best for each individual [13] so that interventions may be tailored to meet the needs of each patient. Unfortunately, there is currently a dearth of strategies for identifying specific patients at risk for attrition early in antidepressant treatment based on potentially modifiable factors.

Specific beliefs and attitudes about illness and medications - such as concerns about overuse, harmfulness or side effects - have been associated with a lack of adherence to dosing recommendations or persistence in treatment [14-17]. Attitudes about treatment are specific to individuals and may also be modifiable during treatment, making attitudes a potentially useful data source for the identification of patients at risk for attrition.

Explicitly asking patients about their intent to continue in treatment may be the most direct method for obtaining data on patient attitudes $[18,19]$. If intent to attend future visits is related to attrition, this factor could be used as a covariate in statistical analyses to reduce outcome and treatment group bias [18]. More importantly, patient-specific intent to continue coupled with the identification of possible reasons for future discontinuation could be used to tailor evidence-based interventions to retain individual patients.

Side effects and lack of efficacy are common and are primary reasons for dropping out of antidepressant treatment trials that last 6 weeks or longer (dropout rates of $3.7-19.8$ and $2.1-9.9 \%$, respectively $[5,20])$. In a naturalistic setting, $55 \%$ of the patients on serotonin reuptake inhibitors reported at least 1 bothersome side effect within about 3 months of starting treatment and these patients were about 3 times more likely to drop out [6].

This report evaluates participants' intent to attend future treatment visits overall and in the context of side effects or not getting better. It uses data from the Suicide Assessment Methodology Study of the Depression Trials Network of the National Institute of Mental Health to address the following questions: can attrition be predicted using participants' self-reported intent to (a) attend the next treatment visit, (b) remain in the study until completion, or (c) remain in the study if experiencing side effects or lack of efficacy?

We anticipated that participants who report a negative or uncertain intent to continue in the study in response to these questions are more likely to drop out. We also explore how the actual experiences of side effects or lack of efficacy during the study are related to participants' earlier reported intent to remain in the study.

\section{Methods}

\section{Study Description}

The primary objective of the Suicide Assessment Methodology Study was to develop easy-to-use clinician- and patient-friendly measures of suicidality and associated symptoms. The Institutional Review Boards at the National Coordinating Center (the University of Texas Southwestern Medical Center), the Data Coordinating Center and each of 15 regional centers approved and oversaw the study protocol. The participants provided written informed consent prior to study enrollment.

In all, 265 adult outpatients with nonpsychotic MDD, 18-75 years of age, were enrolled at 6 primary and 9 psychiatric care sites across the USA and were self- or professionally referred. The results are therefore more generalizable to real-world clinical settings than those from typical efficacy studies. Nonpsychotic MDD was diagnosed clinically and confirmed with the Psychiatric Diagnostic Screening Questionnaire [21, 22] and an MDD checklist from the Diagnostic and Statistical Manual of Mental Disorders - fourth edition - text revision [23]. The participants were treated with a selective serotonin reuptake inhibitor (SSRI) antidepressant and monitored for 8 weeks. The SSRIs used were at the discretion of the treating physician and could include citalopram, escitalopram, fluoxetine, paroxetine, paroxetine-CR or sertraline. The participants received medications and doses that are routinely received in clinical practice for a duration of time that reflects consensually recommended preferred practices. Clinical research coordinators (CRCs) at each clinical site supported participants and clinicians.

To provide appropriately vigorous yet tolerable dosing, clinical management was informed by critical decision point dosing tables and measurement-based care [24-26]. Measurement-based care included measurement at each clinic visit of (1) depressive symptom severity with the Quick Inventory of Depressive Symptomatology - Clinician-rated (QIDS- $C_{16}$ ) [27-29] and (2) side effects and medication tolerability using the Systematic Assessment for Treatment-Emergent Events - Systematic Inquiry [30], a 55item self-report that rates the most commonly reported side effects expected with the study medications, the 3-item Frequency, Intensity and Burden of Side Effects Rating (FIBSER) [31], a selfreport measure which provides global ratings of frequency, intensity and overall burden due to side effects attributable to the antidepressant treatment, and a self-rated medication treatment adherence questionnaire to assess compliance with the prescribed antidepressant. Measurement-based care was used successfully in clinical practice settings in the Sequenced Treatment Alternatives to Relieve Depression trial $[32,33]$.

Protocol visits were to occur at weeks $0,2,4,6$ and 8 . In addition, the QIDS- $\mathrm{C}_{16}$ and FIBSER were collected by phone at weeks $1,3,5$ and 7 . The participants were also contacted by telephone on Mondays, Wednesdays and Fridays during the first 2 weeks following medication initiation and following a dose increase (week 4 or later) to evaluate the presence of suicidal ideation and emergence of associated symptoms. 
Table 1. Baseline characteristics of the sample

\begin{tabular}{|c|c|}
\hline \multicolumn{2}{|l|}{ Race } \\
\hline White & $170(64.2)$ \\
\hline Black & $64(24.1)$ \\
\hline Other & $31(11.7)$ \\
\hline \multicolumn{2}{|l|}{ Gender } \\
\hline Male & $77(29.1)$ \\
\hline Female & $188(70.9)$ \\
\hline \multicolumn{2}{|l|}{ Employment } \\
\hline Unemployed & $95(36.0)$ \\
\hline Employed & $155(58.7)$ \\
\hline Retired & $14(5.3)$ \\
\hline \multicolumn{2}{|l|}{ Marital status } \\
\hline Never married & $85(32.2)$ \\
\hline Married & $99(37.5)$ \\
\hline Divorced/separated & $70(26.5)$ \\
\hline Widowed & $10(3.8)$ \\
\hline \multicolumn{2}{|l|}{ Insurance } \\
\hline Private & $115(44.4)$ \\
\hline Public & $50(19.3)$ \\
\hline None & $94(36.3)$ \\
\hline \multicolumn{2}{|l|}{ Hispanic } \\
\hline No & $234(88.3)$ \\
\hline Yes & $31(11.7)$ \\
\hline \multicolumn{2}{|l|}{ Age at onset ( $\geq 18$ years) } \\
\hline No & $96(36.6)$ \\
\hline Yes & $166(63.4)$ \\
\hline \multicolumn{2}{|l|}{ Family history of alcohol/drug } \\
\hline No & $144(54.5)$ \\
\hline Yes & $120(45.5)$ \\
\hline \multicolumn{2}{|l|}{ Family history of suicide } \\
\hline No & $256(97.0)$ \\
\hline Yes & $8(3.0)$ \\
\hline \multicolumn{2}{|c|}{ Number of depressive episodes $(\geq 2)$} \\
\hline No & $79(33.8)$ \\
\hline Yes & $155(66.2)$ \\
\hline \multicolumn{2}{|l|}{ Chronic depression ( $\geq 2$ years) } \\
\hline No & $174(71.0)$ \\
\hline Yes & $71(29.0)$ \\
\hline \multicolumn{2}{|l|}{ Anxious features } \\
\hline No & $90(34.0)$ \\
\hline Yes & $175(66.0)$ \\
\hline Age, years & $265[41.2 \pm 13.5]$ \\
\hline Education, years & $264[13.5 \pm 2.8]$ \\
\hline HRSD $_{17}$ (without SI item) & $264[21.5 \pm 4.5]$ \\
\hline QIDS-C $_{16}$ (without SI item) & $265[14.8 \pm 3.2]$ \\
\hline GMC severity & $264[3.2 \pm 3.7]$ \\
\hline
\end{tabular}

Figures are numbers of cases with percentages in parentheses and means \pm SD in square brackets. $\mathrm{HRSD}_{17}=17$-item Hamilton Rating Scale for Depression; QIDS- $\mathrm{C}_{16}=$ Quick Inventory of Depressive Symptomatology (clinician-rated); GMC = general medical condition.

\section{Study Population}

A total of 265 eligible outpatients provided written informed consent and were enrolled and treated from July 2007 through February 2008. Eligible participants had a score $\geq 14$ on the baseline 17-item Hamilton Rating Scale for Depression [34, 35]. Participants with general medical conditions (GMCs) were eligible as long as their GMCs did not contraindicate the use of an SSRI. Patients were ineligible if they had bipolar disorder; schizophrenia; schizoaffective disorder; MDD with psychotic features (lifetime); a current primary diagnosis of anorexia nervosa, bulimia nervosa, or obsessive-compulsive disorder; current substance abuse or dependence; required inpatient treatment at the time of study entry; or had a well-documented history of nonresponse (in the current major depressive episode) to two adequately delivered SSRI treatments. Patients were also ineligible if they were breast-feeding, pregnant, or intending to become pregnant, had taken an antipsychotic medication within 4 months of study entry, or had taken antidepressants in the 2 weeks prior to screening (4 weeks for fluoxetine and 6 weeks for MAOIs). Suicidality was acceptable as long as inpatient treatment was not indicated at the baseline visit.

\section{Assessments}

At the screening/baseline visit, CRCs collected clinical and sociodemographic information and completed the 17-item Hamilton Rating Scale for Depression. At baseline, the participants also completed a 125-item forced-choice (symptom present or absent) self-report DSM-IV axis I screening questionnaire, the Psychiatric Diagnostic Screening Questionnaire and the Self-Administered Comorbidity Questionnaire [36], a 40-item self-report that assesses the presence of a range of common medical conditions. During all clinic visits, including baseline, the CRCs also collected the QIDS- $\mathrm{C}_{16}$, FIBSER and Systematic Assessment for Treatment-Emergent Events - Systematic Inquiry.

At baseline and at the week 2, 4 and 6 clinic visits, the participants responded to the following questions in a self-report format: (1) How likely is it that you will come back for the next treatment visit? (2) How likely is it that you will complete all 8 weeks of the study? (3) If your depression is not getting better, how likely are you to stay in the study? (4) If you are experiencing bothersome side effects, how likely are you to stay in the study?

Each question was rated on a Likert-type scale with 5 possible responses ranging from very unlikely to very likely. Questions 1 and 2 were derived from the approach suggested by Leon et al. [18] and Demirtas and Schafer [19].

Remission was defined as a score of $\leq 5$ on the last available QIDS- $\mathrm{C}_{16}$. The presence of side effects was determined by a FIBSER score of $\geq 3$, reflecting a moderate burden of side effects.

\section{Definition of Attrition}

Dropouts were defined as participants who discontinued attending clinic visits at any point after the baseline visit. Those who left treatment for medical reasons, such as development of a medical condition that contraindicated the study medication, were not considered dropouts.

\section{Analytic Methods}

Descriptive statistics, means and standard deviations for continuous variables, and percentages for discrete variables, were used to characterize the sample. $\chi^{2}$ tests and Fisher's Exact Test 
Table 2. Responses to intent-to-attend questions at baseline $(\mathrm{n}=264)$ and at week $2(\mathrm{n}=213)$

\begin{tabular}{|c|c|c|c|c|c|c|c|c|}
\hline \multirow[t]{2}{*}{ Response } & \multicolumn{2}{|c|}{$\begin{array}{l}\text { Likely to attend next } \\
\text { visit, \% }\end{array}$} & \multicolumn{2}{|c|}{$\begin{array}{l}\text { Likely to complete } \\
8 \text { weeks, } \%\end{array}$} & \multicolumn{2}{|c|}{$\begin{array}{l}\text { Stay if not improving, } \\
\%\end{array}$} & \multicolumn{2}{|c|}{$\begin{array}{l}\text { Stay if having side } \\
\text { effects, \% }\end{array}$} \\
\hline & baseline & week 2 & baseline & week 2 & baseline & week 2 & baseline & week 2 \\
\hline Very likely & 84.5 & 86.4 & 81.1 & 85.0 & 53.0 & 60.1 & 34.9 & 50.7 \\
\hline Likely & 13.3 & 10.8 & 14.8 & 12.6 & 24.2 & 24.4 & 28.8 & 23.9 \\
\hline Not sure & 1.5 & 1.4 & 3.4 & 1.9 & 21.2 & 12.7 & 28.4 & 22.1 \\
\hline Unlikely & 0.0 & 0.5 & 0.0 & 0.0 & 1.2 & 2.3 & 6.4 & 1.9 \\
\hline Very unlikely & 0.7 & 0.9 & 0.7 & 0.5 & 0.4 & 0.5 & 1.5 & 1.4 \\
\hline
\end{tabular}

were applied to test the equality of the probability of attrition among those who provided positive and uncertain/negative responses to the assessment of the intent to attend future visits. $\chi^{2}$ tests were also used to evaluate the association of attrition, the presence of side effects and intent to continue with side effects, as well as attrition, symptom improvement and intent to continue if not improving. All tests were conducted with a 2 -sided alternative hypothesis.

\section{Results}

The characteristics of the sample are reported in table 1 . About a fifth of the sample dropped out (56/264); $4.6 \%(\mathrm{n}=12 / 264)$ by week $2,9.9 \%(\mathrm{n}=26 / 264)$ by week $4,15.5 \%(\mathrm{n}=41 / 264)$ by week 6 and $21.2 \%(\mathrm{n}=56 / 264)$ by week 8 . Remission was significantly less likely for dropouts $(23 \%)$ than for completers $(47 \%)(\mathrm{p}=0.0013)$.

Given the frequency distribution of responses to the questions about future intent (table 2), the positive responses 'very likely' and 'likely' to stay were collapsed to the category 'positive' and the uncertain/negative responses 'not sure,' 'unlikely' and 'very unlikely' to stay were collapsed to the category 'uncertain/negative' for analysis.

Uncertain/negative responses to the questions about coming back for the next treatment visit or completing the study predicted attrition at several time points, but very few participants (2-4\%) responded in this manner (table 3). However, a substantial number of participants were willing to signal negative/uncertain intent at baseline (23-36\%) and at week $2(15-25 \%)$ in response to the questions about side effects or lack of efficacy. An uncertain/negative response at baseline to either of these questions was associated with attrition at weeks 6 and 8 , while an uncertain/negative response to either of these questions at week 2 predicted attrition at weeks 4, 6 and 8 .
There was no association between baseline severity and attrition $(\mathrm{p}=0.9235)$. The odds ratio for the QIDS$\mathrm{C}_{16}$ with a 5 -unit increase was 1.02 , and using the goodness of fit test, the model fits well.

Dropouts who experienced side effects were 3 times more likely to have reported uncertain/negative rather than positive intent about staying in the study with bothersome side effects at baseline (7 vs. $2 \%$ ). Dropouts who did not report side effects were still twice as likely to have reported uncertain/negative rather than positive intent at baseline about staying in the study with side effects $(20$ vs. $10 \%$ ) and 3 times as likely to have reported uncertain/ negative rather than positive intent at week 2 ( $20 \mathrm{vs.} 7 \%$ ). Completers, whether or not they actually experienced side effects during treatment, showed little difference in uncertain/negative versus positive intent to continue at either baseline or week 2 .

Among both dropouts and completers, participants who reported an uncertain/negative intent to continue with lack of improvement had significantly less improvement in symptom severity by the QIDS- $\mathrm{C}_{16}$ than those who reported a positive intent to continue (23 vs. $38 \%$ change in dropouts and 43 vs. $56 \%$ change in completers). There was about a 2-point difference in improvement on the QIDS- $\mathrm{C}_{16}$ in both of these comparisons, a clinically meaningful difference.

\section{Discussion}

Our results indicate that self-reported intent to continue if experiencing side effects and intent to continue even with a lack of initial efficacy are very good markers for attrition. A substantial percentage of participants were willing to express concern or ambivalence at baseline about continuing to attend with side effects (36\%) or 
Table 3. Associations between intent to attend and attrition

\begin{tabular}{|c|c|c|c|c|c|c|c|c|c|c|}
\hline \multirow[t]{3}{*}{ Response } & & \multirow[t]{3}{*}{$\mathrm{n}$} & \multicolumn{8}{|c|}{ Attrition by treatment week } \\
\hline & & & \multicolumn{2}{|c|}{ week 2} & \multicolumn{2}{|c|}{ week 4} & \multicolumn{2}{|c|}{ week 6} & \multicolumn{2}{|c|}{ week 8} \\
\hline & & & $\%$ & $\mathrm{p}$ value & $\%$ & $\mathrm{p}$ value & $\%$ & $\mathrm{p}$ value & $\%$ & $\mathrm{p}$ value \\
\hline \multicolumn{11}{|c|}{ Likely to attend next visit } \\
\hline \multirow[t]{2}{*}{ Baseline } & No & 6 & 0.0 & 0.5887 & 0.0 & 0.4128 & 16.7 & 0.9380 & 16.7 & 0.7829 \\
\hline & Yes & 258 & 4.7 & & 10.1 & & 15.5 & & 21.3 & \\
\hline \multirow[t]{2}{*}{ Week 2} & No & 6 & - & - & 16.7 & 0.0622 & 16.7 & 0.3115 & 50.0 & 0.0067 \\
\hline & Yes & 207 & - & & 2.9 & & 6.3 & & 12.1 & \\
\hline \multicolumn{11}{|c|}{ Likely to complete 8 weeks } \\
\hline \multirow[t]{2}{*}{ Baseline } & No & 11 & 18.2 & 0.0266 & 27.3 & 0.0476 & 36.4 & 0.0513 & 36.4 & 0.2092 \\
\hline & Yes & 253 & 4.0 & & 9.1 & & 14.6 & & 20.6 & \\
\hline \multirow[t]{2}{*}{ Week 2} & No & 5 & - & - & 20.0 & 0.0339 & 40.0 & 0.0023 & 60.0 & 0.0017 \\
\hline & Yes & 208 & - & & 2.9 & & 5.8 & & 12.0 & \\
\hline \multicolumn{11}{|c|}{ Likely to stay if not getting better } \\
\hline \multirow[t]{2}{*}{ Baseline } & No & 60 & 8.3 & 0.1091 & 15.0 & 0.1276 & 30.0 & 0.0004 & 36.7 & 0.0009 \\
\hline & Yes & 204 & 3.4 & & 8.3 & & 11.3 & & 16.7 & \\
\hline \multirow[t]{2}{*}{ Week 2} & No & 33 & - & - & 12.1 & 0.0020 & 21.2 & 0.0002 & 30.3 & 0.0015 \\
\hline & Yes & 180 & - & & 1.7 & & 3.9 & & 10.0 & \\
\hline \multicolumn{11}{|c|}{ Likely to stay with bothersome side effects } \\
\hline \multirow[t]{2}{*}{ Baseline } & No & 96 & 7.3 & 0.1054 & 13.5 & 0.1279 & 24.0 & 0.0043 & 31.3 & 0.0026 \\
\hline & Yes & 168 & 3.0 & & 7.7 & & 10.7 & & 15.5 & \\
\hline \multirow[t]{2}{*}{ Week 2} & No & 54 & - & - & 7.4 & 0.0493 & 14.8 & 0.0047 & 24.1 & 0.0059 \\
\hline & Yes & 159 & - & & 1.9 & & 3.8 & & 9.4 & \\
\hline
\end{tabular}

No = Uncertain/unlikely to continue; Yes = likely to continue.

lack of efficacy (23\%). An uncertain/negative response to either of these questions at baseline and at week 2 predicted attrition, with improved prediction at week 2 for both questions.

Since $58 \%$ of the patients experience at least moderate side effects as early as 1 week after SSRI initiation [37], this improved prediction at week 2 with either the side effect or lack of improvement question may be due to participants basing their retention predictions on actual experience with side effects with the current treatment and/ or a beginning perception of the drug's efficacy.

Since only $2-4 \%$ of the participants expressed a negative or uncertain intent to continue with treatment when asked the more general questions (i.e. likely to attend next visit, likely to complete 8 weeks), questions addressing specific concerns as opposed to general ambivalence are more likely to be useful in clinical practice. Participants may have good intentions at treatment initiation to complete treatment or may be concerned about disappointing their clinicians by expressing a general lack of commitment. Patients who actually experienced side effects prior to dropping out were more likely, at baseline, to have reported an uncertain/negative response about continuing with side effects. Even more strikingly, however, dropouts who did not report side effects were still twice as likely at baseline and 3 times as likely at week 2 to have reported they were uncertain or negative about continuing treatment. In addition to predicting attrition, uncertain or negative responses to the question about continuing to attend if not improving were also associated with a meaningfully lower rate of symptom improvement in both dropouts and completers. This result may be similar to studies that found positive expectations of treatment effectiveness to be associated with improved treatment outcomes in depression [38-40] as well as a possible mechanism in the placebo effect [41].

It is important to resolve adverse events that occur early in treatment [37] and maximize the chances of rapid efficacy with aggressive treatment [42] to help reduce attrition. It is even more proactive, however, to inoculate patients who directly express concerns or ambivalence against discontinuation. Uncertain/negative intent to 
continue with side effects or lack of efficacy may reflect concern about the treatment's possible harmfulness, consideration that depression is not serious enough to tolerate side effects, lack of awareness of the time needed to reach remission, prior negative experiences with side effects or any of a host of other possibilities. However, a noncommittal statement from a patient about continuing in treatment generally, or in the context of side effects or lack of treatment efficacy, is an excellent signal that indicates a potentially less resilient patient. With these patients, it may be helpful for clinicians to conduct an individualized review of patient-specific thoughts regarding side effects and lack of efficacy as well as other concerns about treatment or medication to personalize the focus of educational efforts.

There is evidence that such inoculation may be helpful. Studies have found that patients who discussed adverse events with physicians or pharmacists at the initiation of therapy and those told to continue medication for at least 6 months were less likely to discontinue antidepressant treatment [6], and patients told by their clinician that they might not see a benefit for 2-4 weeks were more likely to be taking their antidepressants 1 month into treatment [4]. These interventions may have modified patient beliefs or their intent to continue, or both. Studies of collaborative care or educational interventions indicate that the provision of educational or supportive interventions that can address topics such as what to do about side effects or the time expected to reach remission may be useful in improving adherence or persistence in taking medications as well as outcomes [4, 6, 43-46]. Personalized responses to each patient's own expressed concerns may be even more useful in retaining less committed, atrisk patients in treatment for a sufficient time to maximize the chances of reaching and sustaining remission with this often chronic or recurrent illness.

The current study has several limitations that may affect its generalizability. The participants received monitored dosing of medications while a CRC supported both clinician and patient. Side effects may not have been identified if they occurred following a visit but prior to dropout. Symptom improvement for completers and dropouts was based on the last available measurement occasion. Data about prior treatment experience were not available. We do not have retention data beyond 8 weeks. Some comparisons had small numbers, making generalizing from the findings difficult. The current study also did not address factors related to clinicians (e.g. experience), clinics (e.g. access and availability of appointments), medication (e.g. complexity of the regimen) or participants (e.g. specific beliefs or attitudes about medication or treatment).

In summary, questions regarding intent to attend future antidepressant treatment visits in the context of side effects or lack of efficacy may be useful clinical tools. They may identify patients with concerns about these issues, as well as patients who may be less resilient to the challenges of completing a course of treatment or have other specific concerns that can be addressed. An individualized review of patient concerns and the individualized tailoring of educational or other interventions may reduce attrition and increase the chances for remission.

\section{Acknowledgments}

This project was funded by the National Institute of Mental Health under Contract N01MH90003 to UT Southwestern Medical Center at Dallas (P.I.: M.H. Trivedi). The content of this publication does not necessarily reflect the views or policies of the Department of Health and Human Services, nor does mention of trade names, commercial products or organizations imply endorsement by the US Government. This analysis was also supported in part by a National Alliance for Research on Schizophrenia and Depression Young Investigator Award (D. Warden). We would also like to acknowledge the editorial support of Jon Kilner, MS, MA.

\section{Disclosures}

D. Warden, PhD, MBA currently owns stock in Pfizer Inc. and has owned stock in Bristol-Myers Squibb Company within the last 5 years.

M.H. Trivedi., MD has been a consultant for Abbott Laboratories Inc., Akzo (Organon Pharmaceuticals Inc.), AstraZeneca, Bayer, Bristol-Myers Squibb Company, Cephalon Inc., Cyberonics Inc., Eli Lilly \& Company, Fabre-Kramer Pharmaceuticals Inc., Forest Pharmaceuticals, GlaxoSmithKline, Janssen Pharmaceutica Products, LP, Johnson \& Johnson PRD, Meade Johnson, Neuronetics, Parke-Davis Pharmaceuticals Inc., Pfizer Inc., Pharmacia \& Upjohn, Sepracor, Solvay Pharmaceuticals Inc., VantagePoint and Wyeth-Ayerst Laboratories. He has served on speaker bureaus for Abdi Brahim, Akzo (Organon Pharmaceuticals Inc.), Bristol-Myers Squibb Company, Cephalon Inc., Cyberonics Inc., Forest Pharmaceuticals, GlaxoSmithKline, Janssen Pharmaceutica Products, LP, Eli Lilly \& Company, Pharmacia \& Upjohn, Solvay Pharmaceuticals Inc., and Wyeth-Ayerst Laboratories. He has also received grant support from Bristol-Myers Squibb Company, Cephalon Inc., Corcept Therapeutics Inc., Cyberonics Inc., Eli Lilly \& Company, Forest Pharmaceuticals, GlaxoSmithKline, Janssen Pharmaceutica, Merck, National Institute of Mental Health, National Alliance for Research in Schizophrenia and Depression, Novartis, Pfizer Inc., Pharmacia \& Upjohn, Predix Pharmaceuticals, Solvay Pharmaceuticals Inc. and Wyeth-Ayerst Laboratories. 
S.R. Wisniewski., $\mathrm{PhD}$ has been a consultant for Cyberonics Inc. (2005-2006), ImaRx Therapeutics Inc. (2006), Bristol-Myers Squibb Company (2007), Organon (2007) and Case-Western University (2007).

I.M. Lesser, MD has received grant support from the National Institute of Mental Health and Aspect Medical Systems, and has served on the speaker bureau of the Medical Education Speakers Network.

J. Mitchell, MD has received research support from BristolMyers Squibb, Jazz Pharmaceuticals, Eli Lilly and Ortho McNeil, has been on the advisory boards of and/or a consultant for Eli Lilly, has been on the speaker bureaus of Eli Lilly and Forest Laboratories, and has equity holdings (excluding mutual funds/ blinded trusts) in Eli Lilly, Forest, Pfizer and Sanofi-Aventis.

M. Fava, MD has received research support from Abbott Laboratories, Alkermes, Aspect Medical Systems, Astra-Zeneca, Bristol-Myers Squibb Company, Cephalon, Forest Pharmaceuticals Inc., GlaxoSmithKline, J \& J Pharmaceuticals, Lichtwer Pharma GmbH, Eli Lilly \& Company, Lorex Pharmaceuticals, Novartis, Organon Inc., PamLab, LLC, Pfizer Inc., Pharmavite, Roche, Sanofi/Synthelabo, Solvay Pharmaceuticals Inc. and Wyeth-Ayerst Laboratories. He has provided advisory/consulting services to Aspect Medical Systems, Astra-Zeneca, Bayer AG, Biovail Pharmaceuticals Inc., BrainCells Inc., Bristol-Myers Squibb Company, Cephalon, Compellis, Cypress Pharmaceuticals, Dov Pharmaceuticals, EPIX Pharmaceuticals, Fabre-Kramer Pharmaceuticals Inc., Forest Pharmaceuticals Inc., GlaxoSmithKline, Grünenthal GmbH, J \& J Pharmaceuticals, Janssen Pharmaceutica, Jazz Pharmaceuticals, Knoll Pharmaceutical
Company, Eli Lilly \& Company, Lundbeck, MedAvante Inc., Novartis, Nutrition 21, Organon Inc., PamLab, LLC, Pfizer Inc, PharmaStar, Pharmavite, Roche, Sanofi/Synthelabo, Sepracor, Solvay Pharmaceuticals Inc., Somerset Pharmaceuticals and Wyeth-Ayerst Laboratories. He has been on speaking bureaus for Astra-Zeneca, Bristol-Myers Squibb Company, Cephalon, Forest Pharmaceuticals Inc., GlaxoSmithKline, Eli Lilly \& Company, Novartis, Organon Inc., Pfizer Inc., PharmaStar and WyethAyerst Laboratories. M.F. has equity holdings (excluding mutual funds/blinded trusts) with Compellis and MedAvante.

A.J. Rush, MD has received research support from the National Institute of Mental Health, the Robert Wood Johnson Foundation and the Stanley Medical Research Institute. He has been on the advisory boards and/or consultant for Advanced Neuromodulation Systems Inc., AstraZeneca, Best Practice Project Management Inc., Bristol-Myers Squibb Company, Cyberonics Inc., Eli Lilly \& Company, Gerson Lehman Group, GlaxoSmithKline, Jazz Pharmaceuticals, Magellan Health Services, Merck \& Co. Inc., Neuronetics, Ono Pharmaceutical, Organon USA Inc., Otsuka Pharmaceuticals, Pam Lab, Personality Disorder Research Corp., Pfizer Inc., The Urban Institute and Wyeth-Ayerst Laboratories Inc. He has been on the speaker's bureau for Cyberonics Inc., Forest Pharmaceuticals Inc. and GlaxoSmithKline, has equity holdings (excluding mutual funds/blinded trusts) in Pfizer Inc. and has royalty income affiliations with Guilford Publications and Healthcare Technology Systems Inc.

G.K. Balasubramani, PhD, Kathy Shores-Wilson, PhD, and Diane Stegman, RN have no disclosures to report.

\section{References}

1 Bockting CL, ten Doesschate MC, Spijker J, Spinhoven P, Koeter MW, Schene AH: Continuation and maintenance use of antidepressants in recurrent depression. Psychother Psychosom 2008;77:17-26.

$\checkmark 2$ Katon W, Von Korff M, Lin E, Bush T, Ormel J: Adequacy and duration of antidepressant treatment in primary care. Med Care 1992;30:67-76

$\checkmark 3$ Maddox JC, Levi M, Thompson C: The compliance with antidepressants in general practice. J Psychopharmacol 1994;8:48-53.

$\checkmark 4$ Lin EH, Von Korff M, Katon W, Bush T, Simon GE, Walker E, Robinson P: The role of the primary care physician in patients' adherence to antidepressant therapy. Med Care 1995;33:67-74.

5 Machado M, Iskedjian M, Ruiz I, Einarson TR: Remission, dropouts, and adverse drug reaction rates in major depressive disorder: a meta-analysis of head-to-head trials. Curr Med Res Opin 2006;22:1825-1837.

6 Bull SA, Hu XH, Hunkeler EM, Lee JY, Ming EE, Markson LE, Fireman B: Discontinuation of use and switching of antidepressants: influence of patient-physician communication. JAMA 2002;288:1403-1409.
7 Melfi CA, Chawla AJ, Croghan TW, Hanna MP, Kennedy S, Sredl K: The effects of adherence to antidepressant treatment guidelines on relapse and recurrence of depression. Arch Gen Psychiatry 1998;55:1128-1132

-8 Demyttenaere K, Adelin A, Patrick M, Walthere D, Katrien DB, Michele S: Six-month compliance with antidepressant medication in the treatment of major depressive disorder. Int Clin Psychopharmacol 2008;23:3642

-9 Warden D, Rush AJ, Wisniewski SR, Lesser IM, Kornstein SG, Balasubramani GK, Thase ME, Preskorn SH, Nierenberg AA, Young EA, Shores-Wilson K, Trivedi MH: What predicts attrition in second step medication treatments for depression? A STAR*D report. Int J Neuropsychopharmacol 2009;12: 459-473.

10 Hirschfeld RM, Dunner DL, Keitner G, Klein DN, Koran LM, Kornstein SG, Markowitz JC, Miller I, Nemeroff CB, Ninan PT, Rush AJ, Schatzberg AF, Thase ME, Trivedi $\mathrm{MH}$, Borian FE, Crits-Christoph P, Keller MB: Does psychosocial functioning improve independent of depressive symptoms? A comparison of nefazodone, psychotherapy, and their combination. Biol Psychiatry 2002; 51:123-133.
11 Rush AJ, Trivedi MH, Wisniewski SR, Nierenberg AA, Stewart JW, Warden D, Niederehe G, Thase ME, Lavori PW, Lebowitz BD, McGrath PJ, Rosenbaum JF, Sackeim HA, Kupfer DJ, Luther J, Fava M: Acute and longer-term outcomes in depressed outpatients requiring one or several treatment steps: a STAR*D report. Am J Psychiatry 2006;163:1905-1917.

12 Insel TR, Quirion R: Psychiatry as a clinical neuroscience discipline. http://www.nimh. nih.gov/about/director/publications/psychiatry-as-a-neuroscience-discipline.shtml (last updated: 6-17-2008, accessed: 6-132008).

13 Mant D: Can randomised trials inform clinical decisions about individual patients? Lancet 1999;353:743-746.

14 Aikens JE, Kroenke K, Swindle RW, Eckert GJ: Nine-month predictors and outcomes of SSRI antidepressant continuation in primary care. Gen Hosp Psychiatry 2005;27:229236.

15 Bultman DC, Svarstad BL: Effects of physician communication style on client medication beliefs and adherence with antidepressant treatment. Patient Educ Couns 2000;40: 173-185. 
16 Hunot VM, Horne R, Leese MN, Churchill RC: A cohort study of adherence to antidepressants in primary care: the influence of antidepressant concerns and treatment preferences. Prim Care Companion J Clin Psychiatry 2007;9:91-99.

-17 Lin EH, Von Korff M, Ludman EJ, Rutter C, Bush TM, Simon GE, Unutzer J, Walker E, Katon WJ: Enhancing adherence to prevent depression relapse in primary care. Gen Hosp Psychiatry 2003;25:303-310.

- 18 Leon AC, Demirtas H, Hedeker D: Bias reduction with an adjustment for participants' intent to dropout of a randomized controlled clinical trial. Clin Trials 2007;4:540-547.

-19 Demirtas H, Schafer JL: On the performance of random-coefficient pattern-mixture models for non-ignorable drop-out. Stat Med 2003;22:2553-2575.

20 Vis PM, van Baardewijk M, Einarson TR: Duloxetine and venlafaxine-XR in the treatment of major depressive disorder: a metaanalysis of randomized clinical trials. Ann Pharmacother 2005;39:1798-1807.

>21 Zimmerman M, Mattia JI: A self-report scale to help make psychiatric diagnoses: the Psychiatric Diagnostic Screening Questionnaire. Arch Gen Psychiatry 2001;58:787794.

-22 Zimmerman M, Mattia JI: The Psychiatric Diagnostic Screening Questionnaire: development, reliability and validity. Compr Psychiatry 2001;42:175-189.

23 American Psychiatric Association: Diagnostic and Statistical Manual of Mental Disorders, ed 4, rev. Washington, American Psychiatric Press, 2000.

-24 Trivedi MH, Rush AJ, Wisniewski SR, Nierenberg AA, Warden D, Ritz L, Norquist G, Howland RH, Lebowitz B, McGrath PJ, Shores-Wilson K, Biggs MM, Balasubramani GK, Fava M: Evaluation of outcomes with citalopram for depression using measurement-based care in STAR*D: implications for clinical practice. Am J Psychiatry 2006; 163:28-40.

-25 Trivedi MH, Rush AJ, Gaynes BN, Stewart JW, Wisniewski SR, Warden D, Ritz L, Luther JF, Stegman D, DeVeaugh-Geiss J, Howland R: Maximizing the adequacy of medication treatment in controlled trials and clinical practice: STAR*D measurementbased care. Neuropsychopharmacology 2007;32:2479-2489.

-26 Trivedi MH, Daly EJ: Measurement-based care for refractory depression: a clinical decision support model for clinical research and practice. Drug Alcohol Depend 2007; 88(suppl 2):S61-S71.
27 Rush AJ, Carmody TJ, Reimitz PE: The Inventory of Depressive Symptomatology (IDS): clinician (IDS-C) and self-report (IDS-SR) ratings of depressive symptoms. Int J Methods Psychiatr Res 2000;9:45-59.

28 Rush AJ, Trivedi MH, Ibrahim HM, Carmody TJ, Arnow B, Klein DN, Markowitz JC, Ninan PT, Kornstein S, Manber R, Thase ME, Kocsis JH, Keller MB: The 16-Item Quick Inventory of Depressive Symptomatology (QIDS), clinician rating (QIDS-C), and self-report (QIDS-SR): a psychometric evaluation in patients with chronic major depression. Biol Psychiatry 2003;54:573-583 (erratum $\mathrm{p}$ 585).

29 Trivedi MH, Rush AJ, Ibrahim HM, Carmody TJ, Biggs MM, Suppes T, Crismon ML, Shores-Wilson K, Toprac MG, Dennehy EB, Witte B, Kashner TM: The Inventory of Depressive Symptomatology, Clinician Rating (IDS-C) and Self-Report (IDS-SR), and the Quick Inventory of Depressive Symptomatology, Clinician Rating (QIDS-C) and SelfReport (QIDS-SR) in public sector patients with mood disorders: a psychometric evaluation. Psychol Med 2004;34:73-82.

30 Levine J, Schooler NR: SAFTEE: a technique for the systematic assessment of side effects in clinical trials. Psychopharmacol Bull 1986;22:343-381.

31 Wisniewski SR, Rush AJ, Balasubramani GK, Trivedi MH, Nierenberg AA: Self-rated global measure of the frequency, intensity, and burden of side effects. J Psychiatr Pract 2006;12:71-79.

32 Fava M, Rush AJ, Trivedi MH, Nierenberg AA, Thase ME, Sackeim HA, Quitkin FM, Wisniewski S, Lavori PW, Rosenbaum JF, Kupfer DJ: Background and rationale for the Sequenced Treatment Alternatives to Relieve Depression (STAR*D) study. Psychiatr Clin North Am 2003;26:457-494, x.

-33 Rush AJ, Fava M, Wisniewski SR, Lavori PW, Trivedi MH, Sackeim HA, Thase ME, Nierenberg AA, Quitkin FM, Kashner TM, Kupfer DJ, Rosenbaum JF, Alpert J, Stewart JW, McGrath PJ, Biggs MM, Shores-Wilson K, Lebowitz BD, Ritz L, Niederehe G: Sequenced Treatment Alternatives to Relieve Depression $\left(\mathrm{STAR}^{*} \mathrm{D}\right)$ : rationale and design. Control Clin Trials 2004;25:119-142.

34 Hamilton M: A rating scale for depression. J Neurol Neurosurg Psychiatry 1960;23:56 62 .

35 Hamilton M: Development of a rating scale for primary depressive illness. Br J Soc Clin Psychol 1967;6:278-296.
36 Sangha O, Stucki G, Liang MH, Fossel AH, Katz JN: The Self-Administered Comorbidity Questionnaire: a new method to assess comorbidity for clinical and health services research. Arthritis Rheum 2003;49:156163.

37 Demyttenaere K, Albert A, Mesters P, Dewe W, De Bruyckere K, Sangeleer M: What happens with adverse events during 6 months of treatment with selective serotonin reuptake inhibitors? J Clin Psychiatry 2005;66:859863.

38 Sotsky S, Glass D, Shea M, Pilkonis P, Collins J, Elkin I, Watkins JT, Imber SD, Leber WR, Moyer J, Oliveri ME: Patient predictors of response to psychotherapy and pharmacotherapy: findings in the NIMH Treatment of Depression Collaborative Research Program. Am J Psychiatry 1991;148:997-1008.

39 Krell HV, Leuchter AF, Morgan MM, Cook IA, Abrams M: Subject expectations of treatment effectiveness and outcome of treatment with an experimental antidepressant. J Clin Psychiatry 2004;65:1174-1179.

40 Imber SD, Pilkonis PA, Sotsky SM, Elkin I, Watkins JT, Collins JF, Shea MT, Leber WR, Glass DR: Mode-specific effects among three treatments for depression. J Consult Clin Psychol 1990;58:352-359.

41 Enck P, Benedetti F, Schedlowski M: New insights into the placebo and nocebo responses. Neuron 2008;59:195-206.

42 Warden D, Rush AJ, Trivedi MH, Fava M, Wisniewski SR: The STAR*D project results: a comprehensive review of findings. Curr Psychiatry Rep 2007;9:449-459.

43 Katon W, Von Korff M, Lin E, Walker E, Simon GE, Bush T, Robinson P, Russo J: Collaborative management to achieve treatment guidelines: impact on depression in primary care. JAMA 1995;273:1026-1031.

$\checkmark 44$ Katon W, Robinson P, Von Korff M, Lin E, Bush T, Ludman E, Simon G, Walker E: A multifaceted intervention to improve treatment of depression in primary care. Arch Gen Psychiatry 1996;53:924-932.

45 Katon W, Von Korff M, Lin E, Simon G, Walker E, Unutzer J, Bush T, Russo J, Ludman E: Stepped collaborative care for primary care patients with persistent symptoms of depression: a randomized trial. Arch Gen Psychiatry 1999;56:1109-1115.

46 Stiefel F, Zdrojewski C, Bel Hadj F, Boffa D, Dorogi Y, So A, Ruiz J, de Jonge P: Effects of a multifaceted psychiatric intervention targeted for the complex medically ill: a randomized controlled trial. Psychother Psychosom 2008;77:247-256. 